\title{
UM LIVRO CHAMADO ANGÚSTIA - SOBRE O ROMANCE DE GRaCILIANO RaMOS
}

\author{
Heloisa Caldas*
}

\section{Resumo}

Para abordar a relação da angústia com a criação, a autora procura na criação literária uma inspiração. A partir do romance Angústia de Graciliano Ramos, o texto mostra alguns aspectos de como nessa narrativa se pode pensar a criação de um objeto de arte - no caso, o romance Angústia - através da própria experiência de angústia, uma vez que nela temos a presença do objeto como causa. A presença do referencial psicanalítico se desdobra em dois planos: o da psicanálise aplicada à literatura e o da literatura aplicada à psicanálise. No primeiro, é considerado o enredo, em que o protagonista vive angústia e a partir dela passa ao ato; no segundo, analisa-se o plano da criação do romance, do qual se deduz a angústia como causa do ato de criação.

Palavras-chave: angústia, psicanálise, literatura, ato

\section{Abstract}

\section{A BOOK NAMED ANGUISH - ON THE ROMANCE By GRACILIANO Ramos}

This paper addresses the relationship between anguish and creativity based on the novel Anguish by Graciliano Ramos. The author shows some aspects of this narrative that can be used to investigate act and creation through the experience of anguish. The use of the psychoanalytical reference is unfolded in two plans: psychoanalysis applied to literature and literature applied to psychoanalysis. In the former, the focus is on the plot, in which the protagonist lives anguish and because of it he is impelled to perform an act; in the latter, the plan of creation of the novel is analyzed and anguish can be inferred as the cause of the creation act.

Keywords: anguish, psychoanalysis, literature, act

\footnotetext{
* Psicanalista, Membro da EBP e da AMP, Mestre em lingüística pela Faculdade de LetrasUFRJ e Doutora em Psicologia pelo Instituto de Psicologia-UFRJ, Professora da UNESA.
} 
Procurando abordar a relação da angústia com a criação, pensei em procurar na criação literária uma inspiração. É bem conhecida a proximidade entre a psicanálise e a literatura assim como o valor da contribuição desta ao ensino e transmissão. Quanto ao tema da angústia, essa relação é bem marcada. J.-A. Miller comenta que o Seminário $A$ angústia de Jacques Lacan poderia ser qualificado como da ordem da criação literária e que Lacan agradeceu à ficção literária por dar estabilidade a experiências fugazes (Miller, 2005: 9). Freud, como bem sabemos, delineou o estranhamento a partir da escrita de Hoffmann (Freud, 1919/1989). O viés da criação permite também perguntar qual o papel da angústia com relação ao saber-fazer do sinthoma: o resultado obtido pelo tratamento analítico de redução do sintoma à sua causa e a invenção de um fazer inédito a partir dela.

Ao longo do tratamento analítico, angústia e sintoma comparecem lado a lado: o tratamento de uma passa pelo do outro. A angústia é tratada pela via do sintoma, por um fazer significante que escreva para o objeto um litoral; por outro lado, o tratamento do sintoma se beneficia da angústia, uma vez que ela é correlata à ruptura na construção significante. Essa ruptura no trabalho repetitivo inconsciente instala as condiçôes para fazer algo de novo com o sintoma, se possível mais reduzido de gozo. Essa, me parece, é a articulação clínica entre angústia e sintoma. Usar a angústia como um sinal do real e, portanto, dar chance ao atravessamento de uma dada realidade sintomática em direção à construção de uma nova.

A escrita literária tem exatamente essa mesma estrutura. Trata-se de uma escrita que, a partir do material consagrado e tradicional da linguagem, propõe uma construção inédita, fruto da estranheza que o familiar pode causar. $\mathrm{O}$ estranhamento pode ser, portanto, o ponto de partida para uma construção que permita uma maneira de viver a realidade fora do senso comum. $\mathrm{O}$ estranhamento, porém, não é exatamente o mesmo que a angústia. Marcus André Vieira destaca, em um artigo seu, a diferença entre o estranhamento e a angústia (Vieira, 2000: 135). Ele comenta as duas portas a que Lacan faz alusão, evocando Virgílio, no Seminário $A$ angústia, e situa o lugar da estranheza como um corredor, um espaço ambíguo entre elas: uma porta se abre para o simbólico e a outra para o real. No estranhamento, portanto, já se verifica que algo anda mal na ordem vigente. $\mathrm{O}$ saber estabelecido vacila, provoca a abertura da porta do simbólico e torna possível passar para esse corredor, lugar do estranhamento. Daí se pode avançar, pela outra porta, para o real, ocasião na qual a angústia propriamente dita é experimentada. A angústia aparece, então, quando o sujeito se defronta com o real, uma vez que o simbólico e o imaginário não permitem mais crença alguma.

Se pensarmos, no entanto, que essa experiência do real provoca novo trabalho de tessitura significante, temos o ato de criação como o efeito da angústia, 
produzido pela angústia. Como Miller aponta, Lacan faz uma operação importante, no Seminário $A$ angústia. Ele assinala o lugar da angústia como sinal do real e como correlato do objeto posicionado aquém do desejo - o objeto como causa -, em vez do objeto visado, objeto do desejo. Lacan passa do modelo de intencionalidade para o de causação do objeto.

Essa via para o real pode ser muito favorável para que se faça um objeto, como um objeto de arte, fruto do desejo que o objeto a causa. Fazer com o "objeto causa" um "objeto a desejar". Este seria o aspecto ativo da angústia, assinalado por J.-A. Miller (2005: 55-56), no desenvolvimento da segunda parte do Seminário de Lacan. Resumindo: a partir da angústia se pode produzir um objeto e oferecêlo ao Outro, como interpretação de seu desejo.

É importante destacar, ainda, que se a angústia se apresenta diante do enigma do desejo do Outro é porque esse desejo do Outro constitui, em si, uma abertura ao real. Por isso ele faz enigma. A pergunta sobre o desejo do Outro só se justifica pelo fato de que o Outro é uma ficção construída, um engano. Não se tem a certeza do desejo do Outro. Certeza que, ao contrário, se tem na angústia, e que me parece corresponder à verificação de que o Outro é da ordem do engano.

A angústia indica essa certeza do engano, o que deixa sem limites o lugar do objeto e exacerba seu caráter diverso daquele do significante. Ela também convoca a criação para que esta, conseqüentemente, produza um trabalho de reparação das bordas que alojam o objeto. Inevitavelmente produzirá novo engano, mas há uma nuança entre as maneiras neuróticas e a da criação propriamente dita ao efetuar esse trabalho.

As maneiras neuróticas, bem afiveladas pela fantasia do sintoma, são o actingout e a passagem ao ato. São reparações que, a partir do "objeto causa", produzem "o objeto fantasmático". A terceira via: a do ato de criação que produz um novo saber, exige que se extraia algo mais da experiência do real; que se abra mão da fantasia, podendo assim passar da fixão à ficção. Não se trata mais de reparar o engano. Muito pelo contrário, trata-se de fazer com o engano!

Buscando, então, um artista que pudesse nos mostrar isto - como se faz um objeto do engano -, tomei o romance de Graciliano Ramos, cujo título é exatamente esse: Angústia (Ramos, 1936/2004). Achei um contraponto interessante: um escritor escreve algo que intitula Angústia sem tratar diretamente dela. No Seminário $A$ angústia, mesmo que Lacan não a tome como conceito, Miller insiste muito nisso, mas como uma via para o real, a palavra angústia é incontável.

Pois bem, no romance Angústia, a palavra "angústia" destaca-se no título, mas não aparece no texto. No entanto, ela está extremamente presente no testemunho que Graciliano nos dá; mais que isso, ele faz da angústia um romance. 
Trata-se de um texto expressionista: a angústia não se define, ela se apresenta. $\mathrm{O}$ leitor é afetado por ela através do personagem, com o personagem, com o autor.

Vou tentar mostrar alguns aspectos desse "fazer a angústia" da narrativa que me levaram a pensar na criação de um objeto de arte chamado angústia, através da própria experiência de angústia, uma vez que nela temos a presença do objeto como causa - o objeto $a$.

Podemos trabalhar em dois planos: psicanálise aplicada à literatura e literatura aplicada à psicanálise. No primeiro, tratamos do enredo em que o protagonista vive angústia e podemos observar o que decorre daí; no segundo, o plano da criação do romance, do qual deduzimos a angústia como causa da criação. $\mathrm{Ou}$ seja, aspectos da angústia como causa da passagem ao ato, pois, no enredo, é disso que se trata, e também como causa da narrativa ficcional e do ato de criação. $\mathrm{O}$ personagem movido pela angústia passa ao ato; o escritor, por sua vez, ao criar o romance, faz um ato.

Graciliano atribui a narrativa ao protagonista, não há um narrador além deste. Graciliano recorreu muito a esse expediente. Ele se coloca na posição que Flaubert aconselha ao artista: "estar na obra como um Deus na criação, invisível e todo poderoso; que seja sentido em toda parte, mas que não seja visto" (cf. Pimentel, 1978: 241). É inevitável, no entanto, reconhecer no personagem a causa de um autor que admitiu, em entrevista, ao ser questionado se sua ficção era autobiográfica: "[...] nunca pude sair de mim mesmo. Só posso escrever o que sou. E se os personagens se comportam de modos diferentes é porque não sou um só” (Senna, 1978: 55).

Feliz solução que ele nos dá. Nada de história do autor no personagem, mas de hystória ${ }^{2}$ causada pelo real. Graciliano começa a escrever Anguistia em 1933, mas só o publica em 1936, ano de sua prisão. Doravante podemos pensar o protagonista Luís da Silva como uma elucubração que responde às causas de Graciliano Ramos. Não se trata, portanto, de uma escrita disjunta de quem a produz, embora não se pretenda pensar aqui que a trama simbólica e imaginária criada para Luís da Silva seja a história confessada de Graciliano. O que destacamos, tomando o texto como testemunho, é a marca de Graciliano, seus dilemas de escritor modernista, sua revolta com a ordem humana já em crise, seu posicionamento político e, de forma mais pessoal, sua chama de paixão e ciúme. Pela sua revolta com a eterna problemática do bem e do mal, podemos colocá-lo na lista dos grandes escritores da humanidade. Mas, pela circunscrição do tema em seu tempo, podemos qualificar Graciliano como um escritor moderno. De fato, nesse romance, o conflito se situa na diferença de classe e na exploração do trabalho em sua forma difusa, indistinta, característica do moderno que, ao mesmo tempo que segrega, ilude 
com a promessa de mobilidade social. Luís da Silva sofria da lógica liberal do início do século que provocou a dissolução do corpus social e a fragmentação da pessoa. Seu destino está em suas mãos e, portanto, seu fracasso é culpa sua.

Dizemos que o mal-estar de nossa contemporaneidade se instala conforme uma lógica pós-moderna, hipermoderna, na qual, seja lá qual for o prefixo, a referência permanece sendo o moderno. É inegável que se trata de uma lógica conseqüente ao moderno: a virada de uma ordem de valores bem estabelecida e fixa para uma ordem de valores relativa, contraditória, inclusive paradoxal. Encontramos, assim, nesse romance, as condições que atualmente estão agravadas e contribuem para a presença tão constante da experiência de angústia na contemporaneidade.

Luís da Silva vive a modernidade. Ele veio do interior, de um mundo rural, para a capital. Seu pai e seu avô tiveram nomes retumbantes, descendência. Ele é um anônimo qualquer na cidade e leva uma "Vida de sururu. Estúpida" (Ramos, 1936/2004: 10). Escreve para o jornal o que lhe pedem, atende a encomendas, um intelectual fracassado num mundo em que não há mais lugar para heróis. Nesse mundo em que predomina a força do dinheiro, ele se atola em dívidas, aluguéis não pagos, empréstimos tomados para agradar a amada. Marina, a moça que mora na casa vizinha e que ele pede em casamento, o deixa por outro mais rico, mais bem-sucedido. Um colega dele. Ele fica nessa vizinhança, assistindo ao namoro dela com Julião Tavares. Este sim, filho de comerciantes bem-sucedidos, astucioso na arte de ganhar dinheiro. Julião pode comprar Marina com sedas e ingressos para o teatro. Luís imagina, passo a passo, a moça sendo seduzida por Julião e testemunha, em seguida, quando Julião a abandona grávida.

Luís acompanha e adivinha Marina em todos esses passos, ouve seus dilemas no banheiro da casa dela, colado ao da sua. Já não sabemos mais se a ama. Parece mais que ele a acompanha para ir até o fundo de sua desilusão com aquele objeto de amor malogrado. Segue-a feito uma sombra para verificar que ela providencia um aborto. Aproxima-se dela na saída dessa operação e a ofende, degradando-a. Ela é e não é a Marina que ele amou. O amor acabou. Como ele diz: "Naturalmente gastei meses construindo essa Marina que vive dentro de mim, que é diferente da outra mas que se confunde com ela" (Ramos, 1936/2004: 82). O ódio a Julião, no entanto, vai crescendo e toma Luís da Silva por inteiro. É preciso que Julião morra. Julião é uma espécie de símbolo político de uma moral corrupta. Um duplo ameaçador ao ideal de Luís da Silva. Julião é o que Luís não pode ser, é outro imaginário.

Essa é a trama. Mas como essa narrativa se desenrola de forma a que se tenha nas mãos que seguram o livro a angústia feito um objeto? Nessa direção, penso 
que algumas observações sobre a angústia e o objeto em função do espaço e do tempo podem ser úteis. Silviano Santiago destaca o caráter fragmentário do romance: "não há palavra certa no lugar certo, porque palavra e lugar perderam o estatuto de certeza conferido pela narrativa realista e objetiva" (Santiago, 2004: 293). Ainda assim não podemos dizer que o romance não seja realista, mas, ao mesmo tempo, confere a essa realidade uma estranheza, pois Graciliano narra o que é vivido subjetivamente por Luís da Silva em função da realidade (Coutinho, 1978: 102).

Temos, então, espaços que se superpõem e se fundem: o da cidade, o das memórias de infância na cidadezinha do interior, o de sua casa de então e a de hoje, ao lado da casa de Marina, o que lhe facilita adivinhar a casa desta e a de todos os vizinhos. O espaço formal do trabalho, informal do café onde os intelectuais jornalistas se encontram e discutem questôes de política, sem chance de acordo. O espaço da classe alta e o seu. Espaços que vão se misturando, se mesclando na narrativa. Esse caleidoscópio vai dando à realidade seu aspecto de irreal. É um espaço favorável ao estranhamento; a moldura lógica e concatenada da realidade se despedaça em inúmeras imagens e o objeto escapa.

As associações parecem obedecer ao fluxo da consciência. Assim, o tempo também é misturado. Como na associação livre, é composto do presente, das memórias de infância e do tempo interior, subjetivo. Essas duas dimensões de espaço e tempo do romance, características vanguardistas da escrita de Graciliano, contribuem para fazer com que ele seja um retalho, uma bricolagem de idéias recortadas. Vive-se com Luís da Silva a divisão subjetiva a cada frase. Nenhuma frase é forte o suficiente para sustentar a ilusão da realidade fantasiada. Todas as idéias são apresentadas em sua face de dúvida, incerteza, estranheza. Elas mostram um sujeito diante de $S(A)$. Deduzimos o $A$ pelos fragmentos das frases. Mas elas não se encadeiam numa lógica de sentido. Elas são frases furadas, digamos assim, em que reina o engodo.

Após o fracasso amoroso, a porta que se abre para Luís é a da morte. Não é bem que ele planeje o crime, ou substancialize a idéia de fazer justiça por suas próprias mãos. Isso seria um acting-out e teria um endereçamento ao Outro. No caso de Luís da Silva, o crime é que parece planejá-lo. Encontramos o crime anunciado, pouco a pouco, através de uma voz superegóica. Ele a atribui inicialmente ao Outro, interpreta o desejo de quem o presenteou com uma corda, Seu Ivo, como anúncio da desgraça. Chega a se destemperar com esse Seu Ivo devido ao presente e tenta recusá-lo. Mas guarda a corda e, lentamente, as imagens de Julião enforcado, entremeadas na narrativa de sua desilusão, vão tomando corpo e força. Ele as rejeita, mas vai se deixando levar, cada vez mais, por elas. 
A morte por enforcamento é fantasmática. Vale lembrar aqui suas memórias do avô com uma cobra enrolada no pescoço, uma cobra-corda; de um poço onde se nadava na infância com as cobras e da cena de seu pai sufocando-o, nesse mesmo poço, para que aprendesse a nadar ${ }^{3}$. Com essas, dentre outras lembranças de mortes e enforcados, Luís começa a andar com esse pedaço de corda no bolso e cada vez mais a se atormentar com a imagem de Julião. A essa altura, o leitor já entrou em seu mundo estilhaçado e aprendeu que os detalhes reaparecem posteriormente dotados de novas funções. Vamos acompanhando a corda e a fantasia de enforcamento de tal forma que sabemos, num tempo anterior ao de Luís, que ele vai enforcar Julião.

Não se tem mais dúvida. Há certeza e angústia. Isso chega ao leitor antes de chegar para o personagem. Este ainda vaga um tanto inconsciente do ato que começa a engendrar. Ele não pensa que vai matar, mas a imagem da morte se impõe a ele. Ele começa a andar atrás de algo. O ritmo da narrativa ganha força e rapidez, há pressa em Luís de se encontrar com algo. Ele supõe Julião por aqui ou acolá, a corromper jovens como Marina. Ele segue Julião numa andança a um bairro mais pobre e distante, onde mora, quem sabe, uma moça fácil de iludir. Ele corre atrás dele e apalpa a corda no bolso. Ele não pode mais perder tempo. Percebe-se que Luís não pensa, ele está na forca. Ele age dominado pela certeza. Ele só pode fazer aquilo. Ele faz o sufocado, o enforcado, o pendurado. Ele se mistura com Julião. Ele se mata em Julião. Confunde-se e sai da realidade. Não sabe sair do lugar do crime, vai errando, tem as mãos feridas da força que fez para sustentar a corda.

O leitor pode até desejar sair também, ele próprio, de dentro do romance. Parar de ler, dar meia volta diante dessa porta do real que Graciliano lhe abriu. Mas é preciso fazer algo, não se pode parar aí. Depois do ato têm-se as conseqüências. O leitor quer saber.

Se Luís fosse herói, provavelmente se matava ou morreria logo depois. Mas Luís é moderno. Ele enlouquece, ele não morre. Alcança a casa e entra num tempo que fusiona todos os tempos, todas as identificações. Tem a impressão de que virão puni-lo, vira seu próprio algoz. O supereu o enlouquece com o gozo do enforcado. Nesse tempo infinito se fundem, após o crime, sua causa primeira e sua culpa anterior. Ele tem alucinações em que vê duplos, juízes, ouve vozes. É no auge dessa despersonalização que o romance acaba e faz com seu início uma articulação topológica.

O romance começara assim: "Levantei-me há cerca de trinta dias, mas julgo que ainda não me restabeleci completamente. Das visões que me perseguiam na- 
quelas noites compridas umas sombras permanecem, sombras que se misturam à realidade e me produzem calafrios" (Ramos, 1936/2004: 7). Logo, toda a narrativa em que Graciliano leva o personagem ao fundo do poço foi posterior ao crime. A narrativa em si é causada por essa experiência do real do personagem e ganha, dessa forma, sua causa maior: a de dar sentido ao que irrompeu com a angústia do personagem. Corresponde a um trabalho posterior que o personagem precisou fazer para extrair as conseqüências de sua passagem ao ato.

Esse trabalho de escrever é, no entanto, apenas suposto ao personagem. $\mathrm{O}$ ato é de Graciliano; ato de criação do romance, mostrando através da angústia, via de entrada e saída, o "objeto causa" e o "objeto de arte": um livro chamado Angústia.

\section{REFERÊNCIAS BIBLIOGRÁFICAS}

Costa Pereira, M. E. (2002). Sim ou não: a angústia e a voz do Outro. Em Besset, V. L. (Org.). Angústia (pp. 105 a 116). São Paulo: Escuta.

Coutinho, C. N. (1978). Graciliano Ramos. Em Sônia Brayner (Org.). Graciliano Ramos, seleção de textos (pp. 73 a 122). Rio de Janeiro: Civilização Brasileira.

Freud, S. (1919/1989). O estranho. ESB, vol. XVII. Rio de Janeiro: Imago.

Lacan, J. (1964/2004). Le Séminaire, livre X: L'angoise. Paris: Seuil.

. (1973/2003). O aturdito. Em Outros escritos (pp. 448 a 497). Rio de Janeiro: Jorge Zahar editor.

(1977/2003). Prefácio à edição inglesa do Seminário 11. Em Outros escritos (pp. 567 a 569). Rio de Janeiro: Jorge Zahar editor.

Miller, J.-A. (2005). Introdução à leitura do Seminário da Angústia de Jacques Lacan. Em

Opção Lacaniana: Revista Brasileira Internacional de Psicanálise, 43, maio de 2005, pp.

7 a 81. São Paulo.

Pimentel, A. F. (1978). Graciliano Ramos e Machado de Assis. Em Sônia Brayner (Org.).

Graciliano Ramos, seleção de textos (238 a 243). Rio de Janeiro: Civilização Brasileira.

Ramos, G. (1936/2004). A anguistia. Rio de Janeiro-São Paulo: Record.

Santiago, S. (2004). Posfácio ao romance. Em Angústia de Graciliano Ramos. São Paulo: Record.

Senna, H. (1978). Revisão do modernismo. Em Sônia Brayner (Org.). Graciliano Ramos, seleção de textos (pp. 46 a 59). Rio de Janeiro: Civilização Brasileira.

Vieira, M. A. (2000). A inquietante estranheza: do fenômeno à estrutura. Em Latusa: Revista da Escola Brasileira de Psicanálise, 4/5, abril de 2000, pp. 124 a 138. Rio de Janeiro. 


\section{Notas}

1 Equívoco proposto por Lacan composto pelos termos ficção e fixação (Lacan, 2003/1973: 484).

2 Lacan reserva a escrita hystoire, misto de histoire e hystérie, para definir o relato histórico que se espera do final de análise causado pelo real e não pela verdade (Lacan, 2003/1977: 568-9).

3 A experiência de sufoco e asfixia também está presente em um conto de Graciliano intitulado Insônia. Esse conto, aliás, serviu de base para um artigo em que a angústia é abordada na sua relação com a voz do Outro (Costa Pereira, 2002: 105-116), publicado na coletânea intitulada Angústia organizada por Vera Lopes Besset.

Recebido em 11 de janeiro de 2006 Aceito para publicação em 16 de março de 2006 